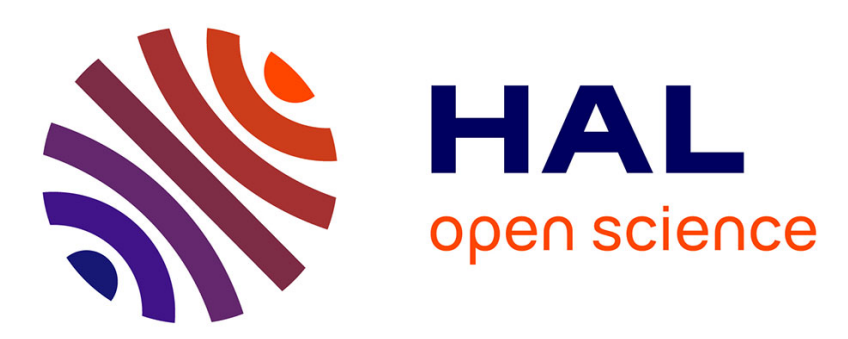

\title{
Role of chemical vs. physical interfacial interaction and adsorbed water on the tribology of ultrathin 2D-material/steel interfaces
}

Taib Arif, Guorui Wang, Rana N Sodhi, Guillaume Colas, Tobin Filleter

\section{- To cite this version:}

Taib Arif, Guorui Wang, Rana N Sodhi, Guillaume Colas, Tobin Filleter. Role of chemical vs. physical interfacial interaction and adsorbed water on the tribology of ultrathin 2D-material/steel interfaces. Tribology International, 2021, 163, pp.107194 (6). hal-03427026

\section{HAL Id: hal-03427026 \\ https://hal.science/hal-03427026}

Submitted on 12 Nov 2021

HAL is a multi-disciplinary open access archive for the deposit and dissemination of scientific research documents, whether they are published or not. The documents may come from teaching and research institutions in France or abroad, or from public or private research centers.
L'archive ouverte pluridisciplinaire HAL, est destinée au dépôt et à la diffusion de documents scientifiques de niveau recherche, publiés ou non, émanant des établissements d'enseignement et de recherche français ou étrangers, des laboratoires publics ou privés. 


\title{
Role of chemical vs. physical interfacial interaction and adsorbed water on the tribology of ultrathin 2D-material/steel interfaces
}

\author{
Taib Arif ${ }^{\sharp \sharp}$, Guorui Wang ${ }^{1 \sharp}$, Rana N.S. Sodhi ${ }^{2}$, Guillaume Colas ${ }^{3}$, Tobin Filleter ${ }^{1^{*}}$ \\ ${ }^{1}$ Department of Mechanical and Industrial Engineering, University of Toronto, Canada \\ ${ }^{2}$ Ontario Centre for the Characterisation of Advanced Materials, Dept. of Chemical Engineering and Applied Chemistry, \\ University of Toronto, Toronto, Ontario, Canada M5S 3E5 \\ ${ }^{3}$ Univ. Bourgogne Franche-Comté FEMTO-ST Institute CNRS/UFC/ENSMM/UTBM, Department of \\ Applied Mechanics, 24 rue de l'Epitaphe, F-25000 Besançon, France
}

Keywords: Nanotribology, $\mathrm{MoS}_{2}$, Graphite, Water adsorption, Physical interaction, 440C Steel, Interfacial Chemistry, Chemical Interaction

Corresponding Authors: *E-mail: filleter@mie.utoronto.ca

\# Equal contribution

\begin{abstract}
Lubrication of steel using 2D-materials has been a growing interest in recent years at the macro/microscale for a wide range of applications including lubricating 440C-steel for satellite and automotive components. This work takes a new approach of comparing the tribological behavior of ultrathin-graphite and ultrathin$\mathrm{MoS}_{2}$ at varying humidity against a custom fabricated 440C steel counter-surface using friction force microscopy. Herein, X-ray Photoelectron Spectroscopy analysis on the 440C-steel counter-surface identified the presence of primarily $\mathrm{Fe}$-oxides with traces of $\mathrm{Mn}$ - and $\mathrm{Cr}$-oxides. The presence of oxides is known to influence the nature (i.e. chemical vs. physical bonding) and strength of the interaction with the basal planes of two-dimensional materials. The stronger chemical interaction between steel/MoS $\mathrm{Mas}_{2}$ found to lead to higher friction, interfacial-shear-strength and adhesion as compared to the steel/ ultrathingraphite interface which exhibits a weaker physical interaction. Water was found to play a contrary role for the two material systems, as it was found to increase both friction and adhesion for the physically interacting interface (steel/ultrathin-graphite), while it was observed to reduce friction for the chemically interacting interface (steel/ $\mathrm{MoS}_{2}$ ). Lastly, adsorbed water was observed to suppress the strong interfacial chemical interaction and act as a temporary protective film between the steel/MoS $\mathrm{S}_{2}$ interface. This behavior is contrary to the macroscopic behavior of $\mathrm{MoS}_{2}$ where water is generally observed to be detrimental to the tribological behavior as it can significantly oxidize $\mathrm{MoS}_{2}$. Since ultrathin- $\mathrm{MoS}_{2}$ undergoes minimal oxidation, it is instead the interaction of surface oxides on the $440 \mathrm{C}$-steel countersurface that dominates the friction behavior.
\end{abstract}




\section{Introduction}

Friction is an everyday phenomenon that costs humanity billions of dollars annually [1]. Mechanical components such as gears and bearings are often manufactured using different steel alloys depending on the application (e.g. 440C-steel for space and automotive applications), which are prone to wear, energy loss and corrosion caused by friction [2]. One approach to minimize friction is coating the contacts with lubricants. Microscale- $\mathrm{MoS}_{2}$ and graphite are well recognized solid lubricants that consist of 2D-structures (2D-MoS 2 and graphene) at the atomic scale. Moreover, ultrathin 2D-MoS 2 and graphene have also been shown to be exceptional solid lubricants due to their unique structures including weak interlayer interaction (van der Waals) [3] and high in-plane strength [4,5].

Ultrathin 2D-materials have demonstrated the ability to lubricate multiscale contacts, ranging from nanoscale to macroscale [2,6-9]. Few layers of graphene and graphite are reported to reduce the coefficient of friction (COF) between microscale 440C-steel/steel and graphite/iron-oxide contacts from $\sim 0.91$ to $\sim 0.15$ while preventing tribo-corrosion and wear. [2,8] Similarly, $\mathrm{MoS}_{2}$ additives can coat microscale-steel/steel interface with ultrathin- $\mathrm{MoS}_{2}$ sheets resulting in the reduction of friction by $\sim 50 \%$ and wear by 5-9 times [10]. Furthermore, 2D-materials can overcome some of the environmental dependency to lubricate contacts as compared to their microscale structures. In dry conditions, graphite is known to exhibit high friction while graphene remains in an ultra-low friction regime [11,12]. Thick$\mathrm{MoS}_{2}$ coatings are sensitive to oxidation from water molecules and atmospheric oxygen, resulting in significant deterioration of the desired tribological performance. However, ultrathin- $\mathrm{MoS}_{2}$ can remain in a low friction regime even with some oxidation and presence of water. It is only after oxidation along the basal plane in excess of $\sim 9.6$ at.\% that ultrathin- $\mathrm{MoS}_{2}$ loses its ultralow friction regime $[13,14]$.

In the absence of water, both $2 \mathrm{D}-\mathrm{MoS}_{2}$ and graphene exhibit friction that is dependent on the sliding counter-surface material (e.g. silicon and silver) despite both the 2D-materials having similar sliding mechanisms [15-17]. This dependency on counter-surface can result in either one of the 2Dmaterial to be more lubricious. At the nanoscale, the dependency of these 2D-materials on counter-surface and the influence of water at specific engineering relevant interfaces is largely unknown due to the commercial unavailability of nanoscale counter-surfaces. This motivates the need for understanding the influence of the specific counter-surface material, such as bearing, gears and valve-grade 440C steel, on the mating interface at the nanoscale. In this work, we take an atomic force microscope (AFM) based approach to compare the tribological properties of ultrathin-graphite and ultrathin-MoS (few layers) against a custom fabricated 440C-steel counter-surface in the presence of varied ambient humidity. First, we identify the surface chemistry on the steel counter-surface and its influence on the interfacial interaction with the respective ultrathin 2D-materials (i.e. few layers). Second, we gain insights on the influence of counter-surface interaction on the sliding and adhesion behavior and identify the role of water at differently interacting interfaces.

\section{Experimental Procedure}

Sample Preparation, AFM Cantilever Fabrication and Characterization. Samples were prepared using a $\mathrm{MoS}_{2}$ crystal (Graphene Supermarket) and highly oriented pyrolytic graphite (SPI supplies) by mechanically exfoliating ultrathin sheets on to an n-doped silicon wafer substrate. As the friction behavior 
of 2D materials including graphene and $\mathrm{MoS}_{2}$ is reported to plateau at approximately 4 layers of thickness and exhibit similar sliding regime to that of bulk material [18], ultrathin sheets with 5-13 layers (1.7 - 4.3 nm for ultrathin-graphite and $3-7.8 \mathrm{~nm}$ for $\mathrm{MoS}_{2}$ ) were used here to minimize the effect of substrate and thickness dependence for both the materials. The wafers were cleaned prior to exfoliation using ethanol first and then followed by methanol in an ultrasonic bath. The AFM cantilevers were fabricated by attaching 440C-steel (Sandvik) powder beads onto a tipless cantilever (APPNano) using PC-Super epoxy under a customized micromanipulator-optical microscope setup. Prior to attaching the bead, the 440C steel bead powder was cleaned in a Bransonic $(\mathrm{M} 1800 \mathrm{H})$ ultrasonic cleaner using ethanol and methanol for $10 \mathrm{~min}$ each. The powder was then suspended on a glass slide and dried in an oven (Cole-Parmer Model 281A) for $30 \mathrm{~min}$ at $40^{\circ} \mathrm{C}$. Minimal epoxy was applied on the cantilever surface, with any excess epoxy being wiped before the bead is attached. The cantilever is submerged in methanol to wash away epoxy residue off the bead surface for $1 \mathrm{~min}$. The cantilever was then imaged using a scanning electron microscope (Hitachi SU3500) to measure the 440C-steel bead diameter of $\sim 12.5 \mu \mathrm{m}$. To ensure the tip geometry doesn't influence the results, we used the same customized cantilever while ensuring experiments were performed in a wear free regime. The maximum normal load only up till $90 \mathrm{nN}$ to ensure it is well within this regime. X-ray photoelectron spectroscopy (XPS) characterization and oxide thickness analysis were performed on the 440C-steel bead powder to identify and estimate the thickness of the surface oxides using an ESCALAB 250Xi (Thermo Fisher Scientific - East Grinstead, UK). ESCALAB $250 \mathrm{Xi}$ is equipped with monochromatic $\mathrm{Al} \mathrm{K}_{\alpha} \mathrm{X}$-ray source. Survey spectra were collected (pass energy (PE) - $100 \mathrm{eV}$ ) using an $\mathrm{Al} \mathrm{K}_{\alpha} \mathrm{X}$-ray (nominal spot size - $400 \mu \mathrm{m}$ ) followed by the spectral regions of interest at higher resolution (PE - $20 \mathrm{eV}$ ) from which the composition (Rel. At.\%) was obtained. All data processing was performed with the system's software (Avantage v. 5.962). XPS characterization on $\mathrm{MoS}_{2}$ sample was also performed to study the influence of water on $\mathrm{MoS}_{2}$ oxidation (Figure 3d). Lastly Raman characterization on mechanically exfoliated $\mathrm{MoS}_{2}$ and HOPG were performed using a Bruker Senterra dispersive microscope (Supporting information; Figure S5).

Tribology Measurements. Surface imaging, friction force microscopy (FFM) and adhesion tests were performed using an Asylum Research MFP 3D atomic force microscope (AFM) system. FFM and adhesion experiments were performed using the 440C-steel beaded cantilever. The normal and torsional stiffness were obtained using the Sader's method [19,20] where the normal stiffness was measured to be $\sim 4.3 \mathrm{~N} / \mathrm{m}$. Lateral sensitivity was obtained using the test probe method [21] using a cleaved potassium bromide block, whereas the normal sensitivity of the cantilever was acquired from the slope of the normal voltage-displacement curve by deflecting the cantilever against a clean silicon wafer. The same steel bead cantilever was used to compare the 2D-materials and minimize any influence of bead topography and defects. A dedicated AFM cantilever mount was used to minimize the error of cantilever orientation misalignment. FFM was performed by scanning the AFM cantilever laterally $\left(90^{\circ}\right.$ scan angle) at scan rate of $\sim 5 \mu \mathrm{m} / \mathrm{s}$. Friction force was calculated by taking half the difference between with trace and retrace lateral signals and multiplied by the lateral sensitivity and lateral stiffness of the cantilever. For FFMcycle testing, scans were done over the same area repeated to observe any change in the friction while maintaining a normal load of $90 \mathrm{nN}$. interfacial shear strength (ISS) measurements were performed by using the generalized Maugis-Dugdale model fitting procedure proposed by Carpick et al. based on the FFM (friction vs. normal load) data in dry conditions [22]. The fitting considered a local asperity on the $440 \mathrm{C}-$ Steel tip in contact with the surface which had a radius measured as $\sim 1.3 \mu \mathrm{m}$ by using a reverse 
imaging procedure reported in the literature [23]. The tip was reverse imaged using the same cantilever holder used for FFM and adhesion tests to ensure the cantilever had the same inclination angle. This ensures that the topography for the area of contact is acquired during reverse imaging. The contacting asperity was identified and the contact radius of the asperity was measured by emulating the geometrical interpenetration of the bead onto the topography of the 2D material surface. This approach was adopted from a previously reported study [23]. Details of the ISS procedure are provided in the SI (Supporting Information; Section S2) [22]. Adhesion experiments were performed with a maximum normal load of 90 $\mathrm{nN}$ and dwell time of $1 \mathrm{~s}$.

Humidity Control and Water Contact Angle (WCA) Measurement. A custom-built environmental chamber was used to control the humidity locally around the contact by controlling the ratio of in-flowing wet and dry nitrogen gas. The wet nitrogen gas was obtained by passing $99.9 \%$ purity $\mathrm{N}_{2}$ gas through a water bubbler. The environment was constantly monitored using an embedded humidity sensor (Honeywell HIH 4000) and allowed to stabilize to ensure minimal drift. The humidity deviation reported herein is the experimental deviation acquired during tests while the sensor has a reported systematic error of $\pm 3.5 \%$ [24]. Water contact angle (WCA) measurements were performed on mechanically exfoliated ultrathin-graphite and $\mathrm{MoS}_{2}$ samples by drop-casting a water droplet $(6 \mu \mathrm{l})$ and analyzed using a customized microscope setup (Supporting Information; Figure S4).

\section{Results and Discussion}

\section{Characterization of $440 \mathrm{C}$-steel bead counter-surface}

A customized 440C-steel bead AFM tip was fabricated and analyzed by reverse AFM imaging to measure the surface roughness and identify the contact point (Figure 1a). Surface chemical characterization was performed using X-ray photoelectron spectroscopy (XPS) on the 440C-steel countersurface which identified the presence of Fe-oxides, with traces of $\mathrm{Mn}$ - and $\mathrm{Cr}$-oxides coming from the steel alloying elements (Figure 1b). Fitting of the Fe2p peak indicated the presence of $\mathrm{FeO}$ and $\mathrm{Fe}_{2} \mathrm{O}_{3}$, whereas the $\mathrm{Cr} 2 p$ peak identified $\mathrm{Cr}_{2} \mathrm{O}_{3}, \mathrm{Cr}(\mathrm{OH})_{3}$ and $\mathrm{CrO}$. Mn-oxides in the form of $\mathrm{MnO}, \mathrm{MnO}_{2}$ and $\mathrm{Mn}_{2} \mathrm{O}_{3}$ were also identified on the surface. An oxide thickness of $5.6 \mathrm{~nm}$ was measured on the countersurface by comparing the relative intensities of the Fe2p and Fe3p peaks (Supporting Information S1).

(a)

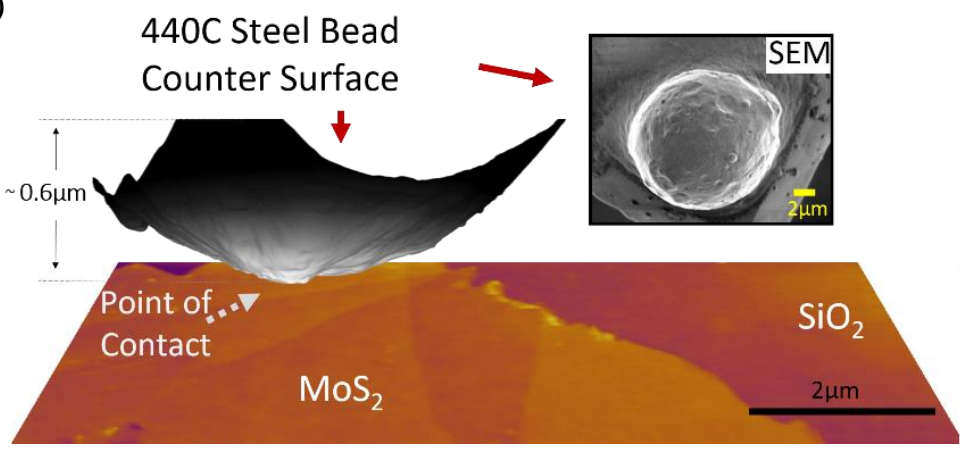

(b)

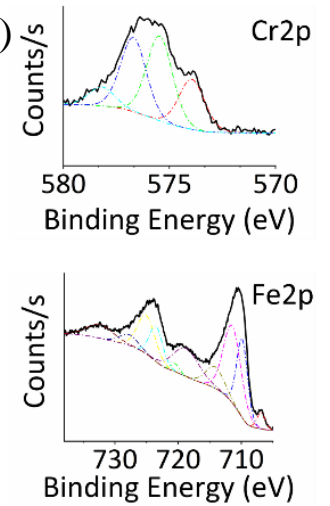

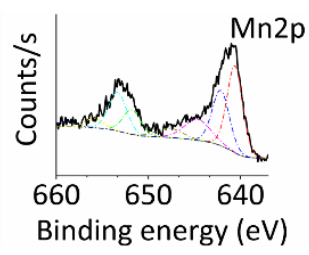

Relative ratio of oxides

Fe - Oxides 1

$\mathrm{Cr}$-Oxides $\quad 0.2$

Mn-Oxides $\quad 0.1$

Fig. 1. (a) Reverse AFM image of 440C-steel bead tip and $\mathrm{MoS}_{2}$ topography. Top-right Inset: SEM image of a 440C-steel beaded tip. b) High resolution XPS spectra on 440C-steel bead powder identifying the presence of $\mathrm{Fe}, \mathrm{Cr}$, and $\mathrm{Mn}$ oxides and their relative ratio with respect to Fe-oxide. 


\section{Friction and adhesion measurements under dry conditions}

Friction and adhesion were measured using friction force microscopy (FFM) for ultrathin-MoS $\mathrm{M}_{2}$ and ultrathin-graphite (5-13 layers) in contact with the steel bead tip under dry conditions by purging a localized AFM chamber with $99.99 \%$ purity $\mathrm{N}_{2}$ (Figure $2 \&$ Table 1). Both friction and adhesion were found to be higher for the steel/ $\mathrm{MoS}_{2}$ interface compared to the $440 \mathrm{C}$-steel/ultrathin-graphite interface as summarized in Table 1. In particular, at the maximum normal load of $90 \mathrm{nN}$, friction on $\mathrm{MoS}_{2}$ was measured to be $\sim 21$ times higher with a lateral force of $42.0 \pm 1.2 \mathrm{nN}$ compared to $2.0 \pm 0.2 \mathrm{nN}$ on ultrathin-graphite. The ISS of the two interfaces was measured by fitting the non-linear friction vs. normal load plot (Figure 2) using the generalized Maugis-Dugdale model proposed by Carpick et al. [22], yielding an ISS of $249 \pm 25 \mathrm{MPa}$ between $440 \mathrm{C}$-steel/MoS 2 and $168 \pm 35 \mathrm{MPa}$ between $440 \mathrm{C}$-steel/ultrathingraphite. These ISS values for 440C-steel/2D-materials reported herein are in similar order of magnitude to the other counter-surface (silicon) typically reported in the literature ( 140 - 173MPa) [7,25].

Furthermore, adhesion on $\mathrm{MoS}_{2}$ was measured to be $\sim 1.6$ times higher with the pull off force of $46 \pm 2 \mathrm{nN}$ compared to $29 \pm 1 \mathrm{nN}$ on ultrathin-graphite (Table 1). Such a trend in pull off force is also in accordance with the obtained adhesive force calculated by fitting friction vs. normal load curves. The comparatively higher friction, ISS and adhesion for the $\mathrm{MoS}_{2}$ suggests a stronger interfacial interaction at the $440 \mathrm{C}$-steel/MoS $\mathrm{M}_{2}$ interface (Table $1 \&$ Table 2) than that for the $440 \mathrm{C}$-steel/ultrathin-graphite interface. According to the classification of the interaction at the interfaces based on interfacial distance or cut off energy, previous studies have reported a physical interaction between steel oxides ( $\mathrm{Fe}-, \mathrm{Cr}$ - and Mn-oxides) with ultrathin-graphite [26-33]. In the case of $\mathrm{MoS}_{2}$ samples, a stronger interaction is expected since all the steel oxides (Fe-, $\mathrm{Cr}$ - and Mn-oxides) are reported to interact preferentially with the sulfur atoms (chemically) on $\mathrm{MoS}_{2}$ and hence can contribute to a more resistive sliding and adhesive behavior with the 440C-steel counter-surface [34-40]. Furthermore, the 440C-steel surface mainly consists of Feoxides (Figure 1b) which are reported to interact strongly via ionic bond like interactions at the Feoxide/ $\mathrm{MoS}_{2}$ interface [40]. Note that, to confirm the differences of interfacial properties between ultrathin$\mathrm{MoS}_{2}$ and ultrathin-graphite are not attributable to a tip change or other instrument changes, AFM measurements were performed with the same tip tests but tests were done in different orders, by alternating between the ultrathin-graphite and $\mathrm{MoS}_{2}$ samples. 


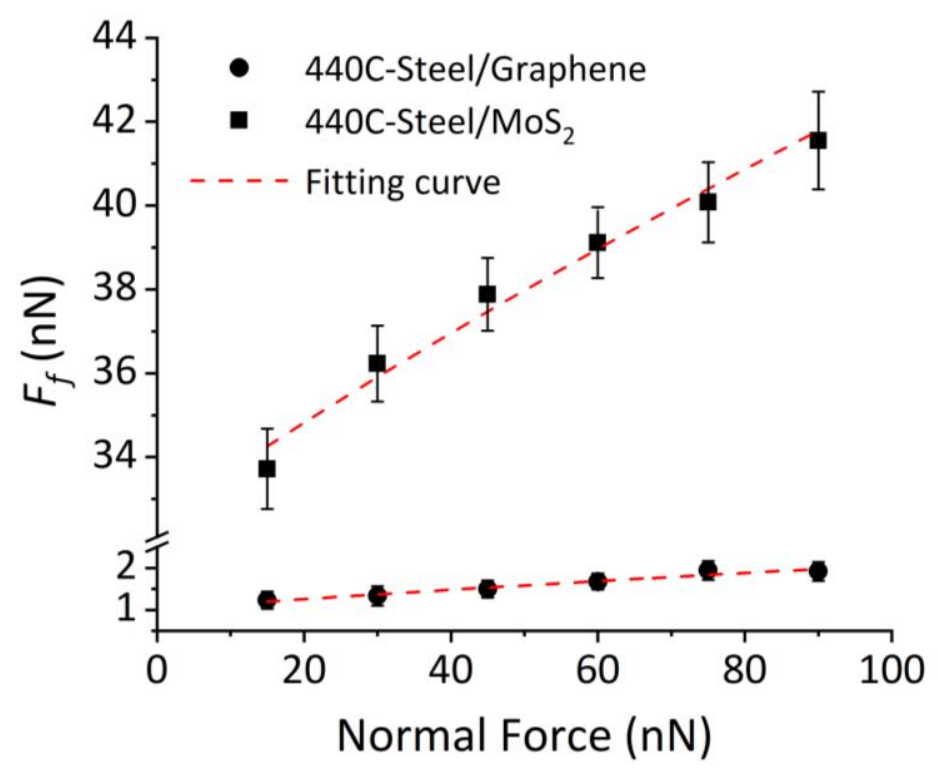

Fig. 2. Friction force as a function of normal load curve for 440C-steel/ultrathin-graphite and 440Csteel/MoS 2 including the generalized Maugis-Dugdale fitting model [22]. Note the break in the friction force axis as $\mathrm{MoS}_{2}$ exhibits significantly higher friction at all normal loads.

Table 1. Experimental sliding and adhesion ( $\mathrm{F}_{\text {Adhesion }}$ ) comparison of $440 \mathrm{C}$-steel $/ \mathrm{MoS}_{2}$ and $440 \mathrm{C}$ steel/ultrathin-graphite interfaces under dry (RH7-9\%) conditions with a maximum normal load $\left(F_{\mathrm{N}}\right)$ of $90 \mathrm{nN}$. Sliding comparisons include friction force $\left(\mathrm{F}_{\text {Friction }}\right)$ and interfacial shear strength (ISS). $\mathrm{F}_{\text {Adhesion,Fit }}$ is the pull off force acquired from the generalized Maugis-Dugdale fitting model on the friction data [22].

\begin{tabular}{|lll|}
\hline & Steel/MoS & Steel/ ultrathin-graphite \\
\hline FFriction [nN] & $42 \pm 1.2$ & $2 \pm 0.3$ \\
ISS [MPa] & $249 \pm 25$ & $168 \pm 35$ \\
FAdhesion $[\mathrm{nN}]_{\text {FAdhesion,Fit [nN] }}$ & $46 \pm 2$ & $29 \pm 1$ \\
\hline
\end{tabular}

Table 2. Summary of the interfacial interaction regimes between different oxides on the 440C-steel surface with respect to $\mathrm{MoS}_{2}$ and ultrathin-graphite.

\begin{tabular}{|lll|}
\hline & MoS $_{2}$ & ultrathin-graphite \\
\hline Fe-oxides & Chemical $[36,37,39,40]$ & Physical [26-30] \\
Cr-oxides & Chemical $[34,36-38]$ & Physical [31] \\
Mn-oxides & Chemical $[34-37]$ & Physical $[32,33]$ \\
\hline
\end{tabular}

Role of water on the interfacial behavior of $440 \mathrm{C}$-steel/ultrathin-graphite and 440C-steel/MoS2 
Next, the role of ambient humidity in both interfacial systems was studied (Figure 3). In the case of 440C-steel/ultrathin-graphite interface, the sliding behavior was found to be minimally influenced by water between $\mathrm{RH} 7-40 \%$, where the friction force was observed to only increase from $\sim 2.0 \pm 0.3 \mathrm{nN}$ to $\sim 3.0 \pm 0.2 \mathrm{nN}$ (Figure 3a). However, a further rise in humidity past RH40\% increased friction by almost three-fold to $\sim 6.0 \pm 0.3 \mathrm{nN}$ as compared to the dry condition. This behavior was repeatable for varying normal loads (Supplementary Information; Figure S1) for two different samples. Adhesion between the 440C-steel/ultrathin-graphite interface at varying humidity was found to increase from $29.0 \pm 1 \mathrm{nN}$ (RH9\%) to $140.0 \pm 2 \mathrm{nN}$ (RH71\%), however, adhesion was only observed to increase by an appreciable value for humidity over RH40\% (Figure 3b). No significant interlayer nor subsurface water intercalation is expected for the ambient conditions studied herein $[12,14]$, therefore the increasing pull off force with humidity is attributed to water meniscus build-up from capillary condensation around the contact and water adsorption $[12,41]$. The overlapping friction-adhesion trend for ultrathin-graphite is suggestive that the increase in friction with humidity between 440C-steel/ultrathin-graphite is primarily due to water adsorption/meniscus build-up. This is consistent with previously reported transitioning interfacial behavior on ultrathin-graphite in contact with other counter surfaces as a result of humidity where water adsorption was considered to play the dominant interfacial role [12,14].

In the case of $\mathrm{MoS}_{2}$, the presence of water was instead observed to reduce friction between the 440C-steel/MoS $\mathrm{Mon}_{2}$ interfaces from $\sim 42.0 \pm 1 \mathrm{nN}$ to $\sim 22.0 \pm 3 \mathrm{nN}$ between RH7- 44\% (Figure 3a). The decreasing friction trend for $440 \mathrm{C}$-steel/ $\mathrm{MoS}_{2}$ interface as a function of humidity was repeatable for 5 datasets, averaging $\sim 43 \%$ reduction (Supporting Information; Figure S2a). The average friction force between $440 \mathrm{C}$-steel/ $\mathrm{MoS}_{2}$ is notably higher than that of $440 \mathrm{C}$-steel/ultrathin-graphite across the whole humidity range. Adhesion experiments between $440 \mathrm{C}$-steel $/ \mathrm{MoS}_{2}$ showed a sharp increase in pull off force from $\sim 46.0 \pm 2 \mathrm{nN}$ (RH10\%) to $\sim 465.0 \pm 10 \mathrm{nN}$ (RH25\%) which occurred at a lower humidity than the transition observed for ultrathin-graphite (Figure 3c). The transition of interfacial adhesion behavior for ultrathin- $\mathrm{MoS}_{2}$ herein at $\sim \mathrm{RH} 25 \%$ is consistent with the observation for microscale-MoS $\mathrm{M}_{2}$ coatings [42] as well as other counter-surfaces for ultrathin- $\mathrm{MoS}_{2}$ [14]. For example in the case of $\mathrm{SiO}_{2}$ countersurfaces, the higher adhesion to ultrathin- $\mathrm{MoS}_{2}$ at a lower humidity (RH25\%) as compared with that for ultrathin-graphite $(>\mathrm{RH} 40 \%)$ was attributed to the comparatively stronger water-MoS $\mathrm{M}_{2}$ interaction resulting from its tri-layer atomic structure [14,43-46]. Furthermore, strength of the capillary force is also reported to be dependent on surface wettability [47]. An increase in surface hydrophobicity weakens the influence of capillary force acting on the counter-surface [47]. Water contact angle (WCA) measurements (Supporting information; Figure S4) show a more hydrophilic $\mathrm{MoS}_{2}\left(\sim 80^{\circ}\right)$ as compared to graphene $\left(\sim 91^{\circ}\right)$. This is suggestive of a stronger capillary force acting between the $440 \mathrm{C}$-steel/ $\mathrm{MoS}_{2}$ than $440 \mathrm{C}$ steel/ultrathin-graphite. The overall pull-off force herein is also generally higher between the 440Csteel/MoS 2 interface as compared to the 440C-steel/ ultrathin-graphite interface which would contribute to an overall higher friction force (Figure 3). In stark contrast with the well-known macroscale behavior of thick- $\mathrm{MoS}_{2}$ coatings, ultrathin-MoS 2 coatings are observed to exhibit a reduction of friction with increasing humidity (Figure 3a). Oxidation of thick- $\mathrm{MoS}_{2}$ form staggered $\mathrm{MoO}_{3}$ structure, which disrupts the 2D van der Waals sliding and hence results in higher friction and wear with increasing humidity $[13,14,48]$. The ultrathin pristine- $\mathrm{MoS}_{2}$ sheets present herein with aligned layers resist oxidation when exposed to water. Figure 3d compares the oxygen content of pristine $\mathrm{MoS}_{2}$ sample before and after exposure to high humidity ambient conditions (RH80\%). XPS characterization shows that exposure of mechanically exfoliated ultrathin- $\mathrm{MoS}_{2}$ sheets underwent minimal oxidation, as oxygen was observed to 
increase from $\sim 4$ at. $\%$ to $\sim 6$ at. $\%$. Some oxygen is expected to be present, since the edges and defect sites are passivated with oxygen and dissociated water molecules.

One thing should be noted that, the humidity dependence of friction for $440 \mathrm{C}$-steel $/ \mathrm{MoS}_{2}$ here is opposite to our previous study, where the $\mathrm{SiO}_{2}$ bead was used for friction testing [14]. Therein, amorphous $\mathrm{SiO}_{2}$ counter-surface interacts weakly with $\mathrm{MoS}_{2}$ by van der Waals interaction, hence water adsorption is dominating the interfacial behavior by increasing the friction. When the $\mathrm{MoS}_{2}$ was oxidized intentionally by heat treatment, the friction was seen to further increase. In contrast, in the present study, steel countersurface exhibits a stronger interaction with the sulfur atoms, while the water is shown not to oxidize the $\mathrm{MoS}_{2}$.
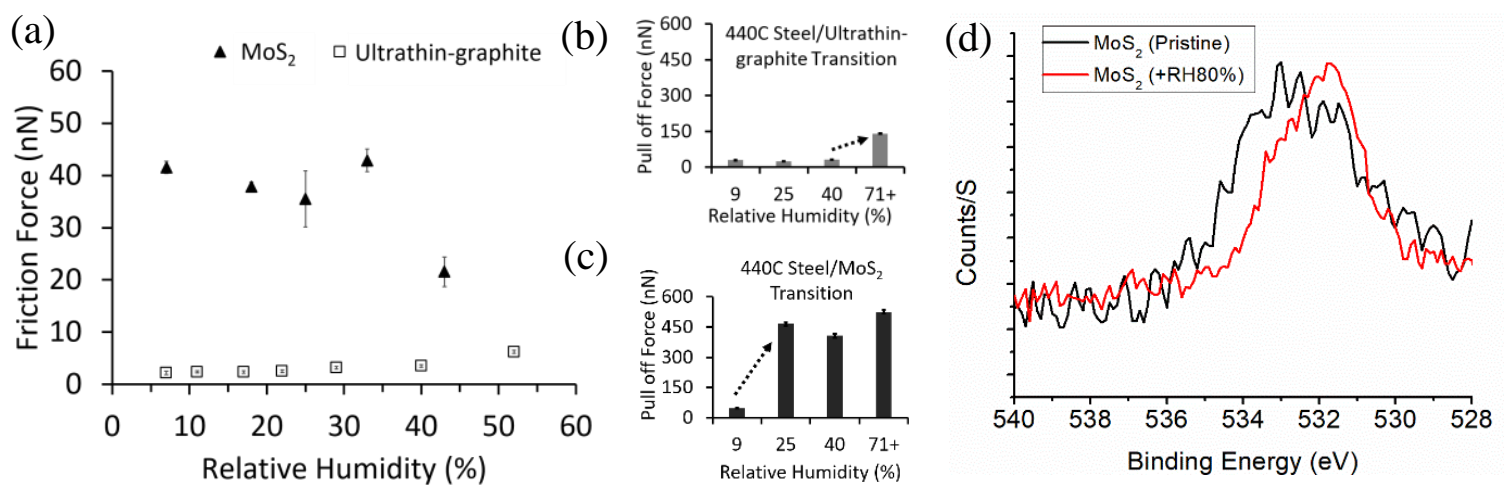

Fig. 3. (a) Average friction force comparison of $\mathrm{MoS}_{2}$ and ultrathin-graphite against a 440C-steel bead counter-surface as a function of humidity. Normal load of $90 \mathrm{nN}$ was applied. (b) Effect of humidity on adhesion between 440C-steel/ultrathin-graphite. (c) Effect of humidity on adhesion between 440Csteel/MoS $\mathrm{M}_{2}$ (d) High-resolution XPS of O1s oxygen peak of pristine- $\mathrm{MoS}_{2}$ and high humidity exposed $\mathrm{MoS}_{2}$.

Interestingly, the friction and adhesion behavior for the $440 \mathrm{C}$-steel/ $\mathrm{MoS}_{2}$ interface do not overlap (i.e. the major variations occur at different humidity), suggesting that there is an alternate mechanism other than oxidation and meniscus effects that contributes to the tribological behavior of $440 \mathrm{C}$-steel/MoS $\mathrm{M}_{2}$ herein at nanoscale. Studies which have observed opposite friction and adhesion trends report alternative interfacial mechanisms dominating the behavior, such as normal load, interfacial electronic interaction and tip-sample distance [49]. To gain further insight into the role of water on the 440C-steel/MoS 2 sliding interface, FFM over multiple sliding cycles was performed at RH9\% and RH42\% (Figure 4) while ensuring a wear free interfacial sliding regime (Supporting Information; Figure S2 and S3). Note that, the formation of chemical bonding at 440C-steel/ $\mathrm{MoS}_{2}$ interface does not necessarily cause the wear failure. While the interfacial energy of metal-oxide/MoS $2\left(\sim 0.1 \mathrm{~J} / \mathrm{m}^{2}\right)$ is comparable to the adhesion energy between $\mathrm{MoS}_{2}$ layers $\left(\sim 0.174 \mathrm{~J} / \mathrm{m}^{2}\right)$, [50,51] the contact area is six orders lower than the $\mathrm{MoS}_{2}$ flake area, thus making the debonding and wear unlikely. Similar to earlier results (Figure 3), friction at RH42\% was found to be lower than RH9\% (first cycle). At low humidity (RH9\%), friction as a function of cycle shows no significant change (grey band). The steady cyclic friction behavior at RH9\% indicates an unchanged sliding contact since very minimal water is expected to adsorb on the $\mathrm{MoS}_{2}$ surface resulting in a direct interaction between the 440C-steel/ $\mathrm{MoS}_{2}$ surface. At high humidity (RH42\%), there is more surface water adsorption [14] which can sandwich and separate the 440C-steel/MoS $\mathrm{M}_{2}$ interface (440C- 
steel/water/MoS ${ }_{2}$. The thickness of interfacial water continuously increases with rising humidity by weakly adsorbing on the 440C-steel surface forming a liquid like structure [52]. At RH42\%, it takes several cycles ( $\sim 4$ cycles) for friction to stabilize (grey band) indicating a change in sliding contact from the removal of adsorbed water before exhibiting friction of the $440 \mathrm{C}$-steel/ $/ \mathrm{MoS}_{2}$ interface that is similar to the RH9\% measurements (Figure 4). The reduction in friction at RH42\% and the friction-cycle behavior infers that the presence of water between the $440 \mathrm{C}$-steel/ $\mathrm{MoS}_{2}$ interface can reduce friction and act as a temporary protective film. Adsorbed water between $440 \mathrm{C}$-steel/MoS $\mathrm{M}_{2}$ rubs off during sliding as water is weakly bonded on both the $440 \mathrm{C}$-steel and $\mathrm{MoS}_{2}$ surfaces [43,52]. It was earlier established (Table 2) that oxides (Fe-, Cr-, and Mn- oxides) on the 440C-steel surface interact strongly (chemically) with the sulfur atoms in $\mathrm{MoS}_{2}$ hence separation of the $440 \mathrm{C}$-steel/ $\mathrm{MoS}_{2}$ interface by water suppresses the strong interfacial interaction resulting in lower friction force. Once the temporary water protective film is removed with the increase in the number of cycles, friction stabilizes and converges into the grey band regardless of the humidity (Figure $4 \&$ Supporting Information; Figure S2b).

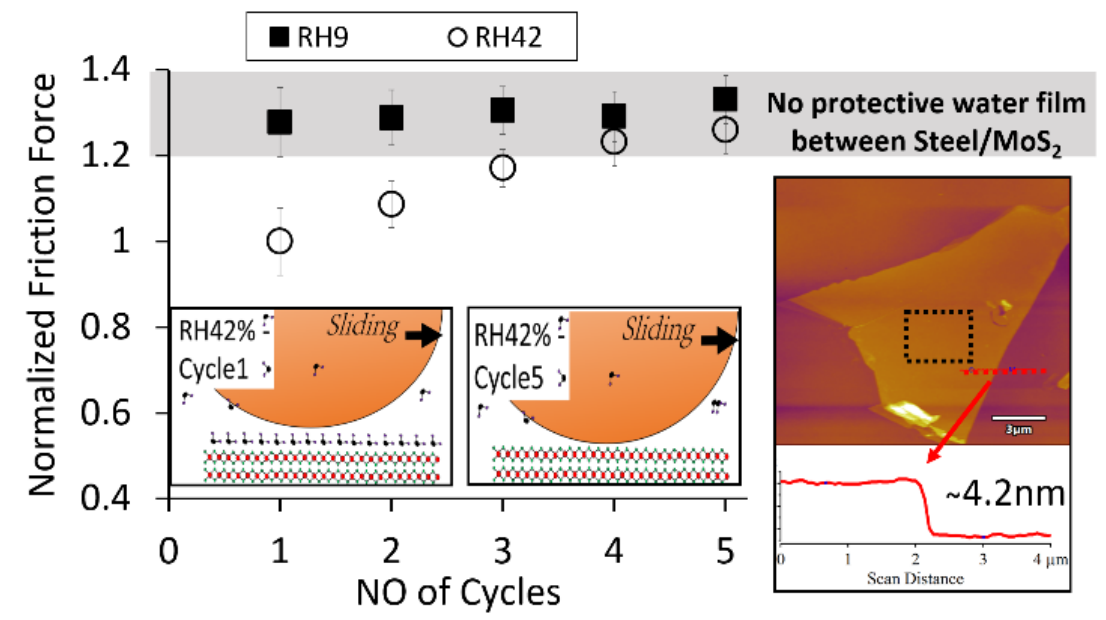

Fig. 4. Normalized friction force between $440 \mathrm{C}$-steel/MoS 2 at RH9\% and RH42\% as a function of scan cycles with normal load of $90 \mathrm{nN}$. Friction was normalized relative to the minimum data point (friction for $1^{\text {st }}$ cycle at RH42\%). "\# of cycles" represents the number of times the same area was scanned repeatedly. The grey background highlights the friction range once the water film is removed between the $440 \mathrm{C}$-steel/ $\mathrm{MoS}_{2}$ contact. Bottom-left inset: Schematic of $440 \mathrm{C}$-steel/MoS $\mathrm{S}_{2}$ interface during the $1^{\text {st }}$-cycle at RH42\% where water separates the $440 \mathrm{C}$-steel/ $\mathrm{MoS}_{2}$ interface. Bottom-center inset: Schematic of $440 \mathrm{C}-$ steel/MoS 2 interface during $5^{\text {th }}$-cycle at $\mathrm{RH} 42 \%$ after water is rubbed off the $\mathrm{MoS}_{2}$ surface. Bottom-right Inset: $\mathrm{MoS}_{2}$ topography indicating the area of interest (dashed black square) and $\mathrm{MoS}_{2}$ thickness (solid red line).

This work focuses on understanding the tribology of both ultrathin-graphite and ultrathin- $\mathrm{MoS}_{2}$ sliding in contact with a 440C-steel beaded counter-surface. XPS revealed the surface chemistry of the 440C-steel counter-surface which consists primarily of Fe-oxides and with appreciable regions of $\mathrm{Mn}$ and $\mathrm{Cr}$-oxides from the alloying elements. The presence of the Fe-, $\mathrm{Cr}$-, Mn-oxides on the 440C-steel surface influence the interfacial interaction regime when in contact with ultrathin-graphite (physical bonding) and $\mathrm{MoS}_{2}$ (chemical bonding) surfaces. The stronger chemical like interaction between 440Csteel/MoS $\mathrm{M}_{2}$ led to higher friction, ISS and adhesion as compared to the weaker physical interaction between 440C-steel/ultrathin-graphite at all levels of humidity. Water was observed to play a contrary role as it 
was found to increase both friction and adhesion for the physically interacting interface (440C-steel/ ultrathin-graphite) yet was observed to reduce friction for the chemically interacting interface (440Csteel/MoS 2 ). By sandwiching between the $440 \mathrm{C}$-steel/MoS $\mathrm{M}_{2}$ interface, adsorbed water molecules suppress the strong interfacial chemical interaction and acts as a temporary lubricating film. The short-lasting effect of water on ultrathin- $\mathrm{MoS}_{2}$ is unique to its size scale as thick-MoS 2 coatings are known to be sensitive to humidity [53]. Lastly, the nanoscale tribological behavior of ultrathin- $\mathrm{MoS}_{2}$ is oppositely influenced by water as compared to the macroscale- $\mathrm{MoS}_{2}$ against $440 \mathrm{C}$-steel. This is attributed to the impact water has on $\mathrm{MoS}_{2}$ at different scales (macroscale vs ultrathin) and the interfacial mechanism dominating the behavior. At the nanoscale, the direct presence of water molecules within the contact change the surface interaction and dominate the sliding behavior whereas at macroscale it is the oxidizing role of water which changes the chemical properties of the interface material that dominates the tribology.

\section{Acknowledgements}

T.A. and G.W. contributed equally to this work. The authors acknowledge financial support from the Ontario Ministry of Research and Innovation Early Researcher Award; the Erwin Edward Hart Endowed

Professorship; the Natural Sciences and Engineering Research Council of Canada (NSERC); and the Canada Foundation for Innovation (CFI).

\section{Reference}

[1] Holmberg K, Erdemir A. Influence of tribology on global energy consumption , costs and emissions. Friction 2017;5:263-84.

[2] Berman D, Erdemir A, Sumant A V. Few layer graphene to reduce wear and friction on sliding steel surfaces. Carbon 2013;54:454-9. https://doi.org/10.1016/j.carbon.2012.11.061.

[3] Ru G, Qi W, Tang K, Wei Y, Xue T. Interlayer friction and superlubricity in bilayer graphene and MoS2/MoSe2 van der Waals heterostructures. Tribology International 2020, 151, 106483.

[4] Bunch JS, Verbridge SS, Alden JS, Van Der Zande AM, Parpia JM, Craighead HG, et al. Impermeable atomic membranes from graphene sheets. Nano Lett 2008;8:2458-62. https://doi.org/10.1021/n1801457b.

[5] Castellanos-Gomez A, Poot M, Steele GA, Van Der Zant HSJ, Agraït N, Rubio-Bollinger G. Elastic properties of freely suspended MoS2 nanosheets. Adv Mater 2012;24:772-5. https://doi.org/10.1002/adma.201103965.

[6] Fasihi P, Kendall O, Abrahams R, Mutton P, Lai Q, Qiu C, Yan W. Effect of graphite and MoS2 based solid lubricants for application at wheel-rail interface on the wear mechanism and surface morphology of hypereutectoid rails. Tribology International 2021, 157, 106886.

[7] Chen H, Filleter T. Effect of structure on the tribology of ultrathin graphene and graphene oxide films. Nanotechnology 2015;26:135702. https://doi.org/10.1088/0957-4484/26/13/135702.

[8] Motozuka S, Sato H, Muramatsu Y, Morinaga M. Interfacial effect between graphite and iron 
substrate on basal plane orientation and lubricity of graphite. Tribology International 2020, 151, 106455

[9] Zhao J, He Y, Wang Y, Wang W, Yan L, Luo J. An investigation on the tribological properties of multilayer graphene and MoS2 nanosheets as additives used in hydraulic applications. Tribology International 2016, 97, 14-20.

[10] Kalin M, Kogovšek J, Remškar M. Mechanisms and improvements in the friction and wear behavior using MoS 2 nanotubes as potential oil additives. Wear 2012;280:36-45. https://doi.org/10.1016/j.wear.2012.01.011.

[11] Berman D, Erdemir A, Sumant A V. Graphene: A new emerging lubricant. Mater Today 2014;17:31-42. https://doi.org/10.1016/j.mattod.2013.12.003.

[12] Arif T, Colas G, Filleter T. Effect of Humidity and Water Intercalation on the Tribological Behavior of Graphene and Graphene Oxide. ACS Appl Mater Interfaces 2018;10:22537-44. https://doi.org/10.1021/acsami.8b03776.

[13] Curry JF, Wilson MA, Luftman HS, Strandwitz NC, Argibay N, Chandross M, et al. Impact of Microstructure on $\mathrm{MoS}_{2}$ Oxidation and Friction. ACS Appl Mater Interfaces 2017;9:28019-26. https://doi.org/10.1021/acsami.7b06917.

[14] Arif T, Yadav S, Colas G, Singh CV, Filleter T. Understanding the Independent and Interdependent Role of Water and Oxidation on the Tribology of Ultrathin Molybdenum Disulfide (MoS2). Adv Mater Interfaces 2019;1901246:1-9. https://doi.org/10.1002/admi.201901246.

[15] Zeng X, Peng Y, Lang H, Yu K. Probing the difference in friction performance between graphene and MoS2 by manipulating the silver nanowires. J Mater Sci 2019;54:540-51. https://doi.org/10.1007/s10853-018-2839-6.

[16] Tran Khac BC, Chung KH. Quantitative assessment of friction characteristics of single-layer MoS 2 and graphene using atomic force microscopy. J Nanosci Nanotechnol 2016;16:4428-33. https://doi.org/10.1166/jnn.2016.11004.

[17] Vazirisereshk MR, Ye H, Ye Z, Otero-de-la-Roza A, Zhao M-Q, Gao Z, et al. Origin of Nanoscale Friction Contrast between Supported Graphene, MoS2 , and a Graphene/MoS2 Heterostructure. Nano Lett 2019;19:5496-505. https://doi.org/10.1021/acs.nanolett.9b02035.

[18] Lee C, Li Q, Kalb W, Liu XZ, Berger H, Carpick RW, et al. Frictional Characteristics of Atomically Thin Sheets. Science 2010;328:76-80. https://doi.org/10.1126/science.1184167.

[19] Sader JE, Chon JWM, Mulvaney P. Calibration of rectangular atomic force microscope cantilevers. Rev Sci Instrum 1999;70:3967-9. https://doi.org/10.1063/1.1150021.

[20] Green CP, Lioe H, Cleveland JP, Proksch R, Mulvaney P, Sader JE. Normal and torsional spring constants of atomic force microscope cantilevers. Rev Sci Instrum 2004;75:1988-96. https://doi.org/10.1063/1.1753100.

[21] Cannara RJ, Eglin M, Carpick RW. Lateral force calibration in atomic force microscopy: A new lateral force calibration method and general guidelines for optimization. Rev Sci Instrum 2006;77:053701. https://doi.org/10.1063/1.2198768. 
[22] Carpick RW, Ogletree DF, Salmeron M. A General Equation for Fitting Contact Area and Friction vs Load Measurements. J Colloid Interface Sci 1999;211:395-400.

https://doi.org/10.1006/jcis.1998.6027.

[23] Pajovic S, Colas G, Saulot A, Renouf M, Filleter T. Work of Adhesion Measurements of MoS2 Dry Lubricated 440C Stainless Steel Tribological Contacts. Adv Eng Mater 2017;1700423:1-10. https://doi.org/10.1002/adem.201700423.

[24] Honeywell International Inc. - Sensing and Control. Data sheet HIH-4000 Series. 2010. (retrieved from https://sensing.honeywell.com/honeywell-sensing-hih4000-series-product-sheet-009017-5en.pdf)

[25] Liu Z, Zhang SM, Yang JR, YangLiu JZ, Yang YL, Zheng QS. Interlayer shear strength of single crystalline graphite. Acta Mech Sin Xuebao 2012;28:978-82. https://doi.org/10.1007/s10409012-0137-0.

[26] Restuccia P, Righi MC. Tribochemistry of graphene on iron and its possible role in lubrication of steel. Carbon N Y 2016;106:118-24. https://doi.org/10.1016/j.carbon.2016.05.025.

[27] Sharifi T, Gracia-Espino E, Reza Barzegar H, Jia X, Nitze F, Hu G, et al. Formation of nitrogendoped graphene nanoscrolls by adsorption of magnetic $\gamma$-Fe2O3 nanoparticles. Nat Commun 2013;4:1-9. https://doi.org/10.1038/ncomms3319.

[28] Susi T, Kaukonen M, Havu P, Ljungberg MP, Ayala P, Kauppinen EI. Core level binding energies of functionalized and defective graphene. Beilstein J Nanotechnol 2014;5:121-32. https://doi.org/10.3762/bjnano.5.12.

[29] Singh V, Joung D, Zhai L, Das S, Khondaker SI, Seal S. Graphene based materials: Past, present and future. Prog Mater Sci 2011;56:1178-271. https://doi.org/10.1016/j.pmatsci.2011.03.003.

[30] Zhou J, Song H, Ma L, Chen X. Magnetite/graphene nanosheet composites: Interfacial interaction and its impact on the durable high-rate performance in lithium-ion batteries. RSC Adv 2011;1:782-91. https://doi.org/10.1039/c1ra00402f.

[31] Dabaghmanesh S, Neek-Amal M, Partoens B, Neyts EC. The formation of Cr2O3 nanoclusters over graphene sheet and carbon nanotubes. Chem Phys Lett 2017;687:188-93. https://doi.org/10.1016/j.cplett.2017.09.005.

[32] Yamada Y, Suzuki Y, Yasuda H, Uchizawa S, Hirose-Takai K, Sato Y, et al. Functionalized graphene sheets coordinating metal cations. Carbon 2014;75:81-94. https://doi.org/10.1016/j.carbon.2014.03.036.

[33] Wu Z, Ren W, Wang D, Li F, Liu B, Cheng H. High-Energy MnO2 Nanowire/Graphene and Graphene Asymmetric Electrochemical Capacitors. ACS Nano 2010;4:5835-42. https://doi.org/10.1021/nn101754k.

[34] Didziulis S, Fleischauer P. Applications of Surface Science to Solid Lubricants. Aerosp Reports 1993.

[35] Lince JR, Stewart TB, Fleischauer PD, Yarmoff JA, Taleb-Ibrahimi A. Chemical Interaction of Mn With the MoSs (0001) Surface Studied by High-Resolution Photoelectron Spectroscopy. J Vac Sci Technol A Vacuum, Surfaces, Film 1989;7:2469-74. 
[36] Yue Q, Chang S, Qin S, Li J. Functionalization of monolayer MoS 2 by substitutional doping: A first-principles study. Phys Lett A 2013;377:1362-7. https://doi.org/10.1016/j.physleta.2013.03.034.

[37] Li D, Niu Y, Zhao H, Liang C, He Z. Electronic and magnetic properties of 3d-metal trioxides superhalogen cluster-doped monolayer MoS 2: A first-principles study. Phys Lett A 2014;378:1651-6. https://doi.org/10.1016/j.physleta.2014.04.008.

[38] Smyth CM, Addou R, McDonnell S, Hinkle CL, Wallace RM. Contact metal-MoS2interfacial reactions and potential implications on MoS2-based device performance. J Phys Chem C 2016;120:14719-29. https://doi.org/10.1021/acs.jpcc.6b04473.

[39] Lince JR, Stewart TB, Hills MM, Fleischauer PD. Photoelectron Spectroscopic Study of The Interaction of Thin Fe Films With The MoS2 (0001) Surface. Surf Sci 1989;223:65-81.

[40] Mos FO, Yin MY, Wang XC, Mi WB, Yang BH. First principles prediction on the interfaces of $\mathrm{Fe} / \mathrm{MoS} 2$, Co/MoS2 and Fe3O4/MoS2. Comput Mater Sci 2015;99:326-35. https://doi.org/10.1016/j.commatsci.2015.01.001.

[41] Peng Y, Wang Z, Li C. Study of nanotribological properties of multilayer graphene by calibrated atomic force microscopy. Nanotechnology 2014;25:305701. https://doi.org/10.1088/09574484/25/30/305701.

[42] Erdemir A. Solid lubricants and self-lubricating films. Mod. Tribol. Handb. Vol. One Princ. Tribol., CRC Press LLC; 2000, p. 787-825. https://doi.org/10.1201/9780849377877.ch22.

[43] Levita G, Restuccia P, Righi MC. Graphene and MoS2 interacting with water: A comparison by ab initio calculations. Carbon 2016;107:878-84. https://doi.org/10.1016/j.carbon.2016.06.072.

[44] Luan B, Zhou R. Wettability and friction of water on a MoS2 nanosheet. Appl Phys Lett 2016;108:131601. https://doi.org/10.1063/1.4944840.

[45] Ortiz-Young D, Chiu H-C, Kim S, Voïtchovsky K, Riedo E. The interplay between apparent viscosity and wettability in nanoconfined water. Nat Commun 2013;4:2482-8. https://doi.org/10.1038/ncomms3482.

[46] Tocci G, Joly L, Michaelides A. Friction of water on graphene and hexagonal boron nitride from $\mathrm{Ab}$ initio methods: Very different slippage despite very similar interface structures. Nano Lett 2014;14:6872-7. https://doi.org/10.1021/n1502837d.

[47] Binggeli M, Mate CM. Influence of capillary condensation of water on nanotribology studied by force microscopy. Appl Phys Lett 1994;65:415-7. https://doi.org/10.1063/1.113020.

[48] Zhao X, Zhang G, Wang L, Xue Q. The Tribological Mechanism of MoS2 Film under Different Humidity. Tribol Lett 2017;65:1-8. https://doi.org/10.1007/s11249-017-0847-3.

[49] Hasz K, Ye Z, Martini A, Carpick RW. Experiments and simulations of the humidity dependence of friction between nanoasperities and graphite: The role of interfacial contact quality. Phys Rev Mater 2018;2:1-9. https://doi.org/10.1103/PhysRevMaterials.2.126001.

[50] Yadav S, Arif T, Wang G, Sodhi RNS, Cheng Y hui, Filleter T, et al. Interfacial Interactions and Tribological Behaviour of Metal-Oxide/2D-Material Contacts. Tribol Lett 2021. 
https://doi.org/10.21203/rs.3.rs-373939/v1.

[51] Sanchez DA, Dai Z, Wang P, Cantu-Chavez A, Brennan CJ, Huang R, et al. Mechanics of spontaneously formed nanoblisters trapped by transferred 2D crystals. Proc Natl Acad Sci U S A 2018;115:7884-9. https://doi.org/10.1073/pnas.1801551115.

[52] Barthel AJ, Gregory MD, Kim SH. Humidity Effects on Friction and Wear Between Dissimilar Metals. Tribol Lett 2012;48:305-13. https://doi.org/10.1007/s11249-012-0026-5.

[53] Zhao X, Zhang G, Wang L, Xue Q. The Tribological Mechanism of MoS2 Film under Different Humidity. Tribol Lett 2017;65:1-8. https://doi.org/10.1007/s11249-017-0847-3. 